\title{
Applying Kalman filter on sensor noise cancelation in grid - connected inverter
}

- Nguyen Minh Huy

- Le Minh Phuong

- Ho Thanh Phuong

Ho Chi Minh city University of Technology, VNU-HCM, Vietnam

(Manuscript Received on July 15, 2015, Manuscript Revised August 30, 2015)

\begin{abstract}
This paper presents the control model of three phase grid- connected photovoltaic inverter based on the analysis of operating principle of two-stage conventional gridconnected inverter. The mathematical model of inverter under dq frame is set up and the overall control strategy of two-stage photovoltaic grid-connected inverter is
\end{abstract}

proposed in this paper. To overcome the distortion general caused by switching effect on sensors, a Kalman filter is introduced. The control strategy was simulated on Matlab Simulink to verify the steady and dynamic of model, improving the quality of electrical power to consumers.

Keywords: Kalman filter, grid-connected, sensor's noise.

\section{INTRODUCTION}

Nowadays fossil fuel is the main energy supplier of the worldwide economy, but the recognition of it as being a major cause of environmental problems makes the mankind to look for alternative resources in power generation [1].

The control strategies applied to distributed systems become of high interest. And how to improve the performance of grid inverter, increase the switching frequency and power density to meet power quality requirements has become a research hotspot in recent years [2].

Many researches are focused to resolve important problems of the distributed system and its control to improve the quality of electrical power such as
Instantaneous reactive power based hysteresis current controller [4], sliding mode controller [5], synchronous reference frame controller etc. have been proposed and developed for a three phase voltage source inverter. The paper [3] investigates the maximum and minimum gain off the PR controller to adapt in case that the grid impedance varies in a wide range. The harmonics in grid voltages and noise in sensing circuit was canceled by a shunt active filter in paper [6]. Recently, the use of second order generalized integrators (SOGI) or linear kalman filters (LKF) has proven to be a more robust strategy for current control in strongly polluted networks [7] by processing voltages independently and even accounting for reduced order harmonics [8]. 


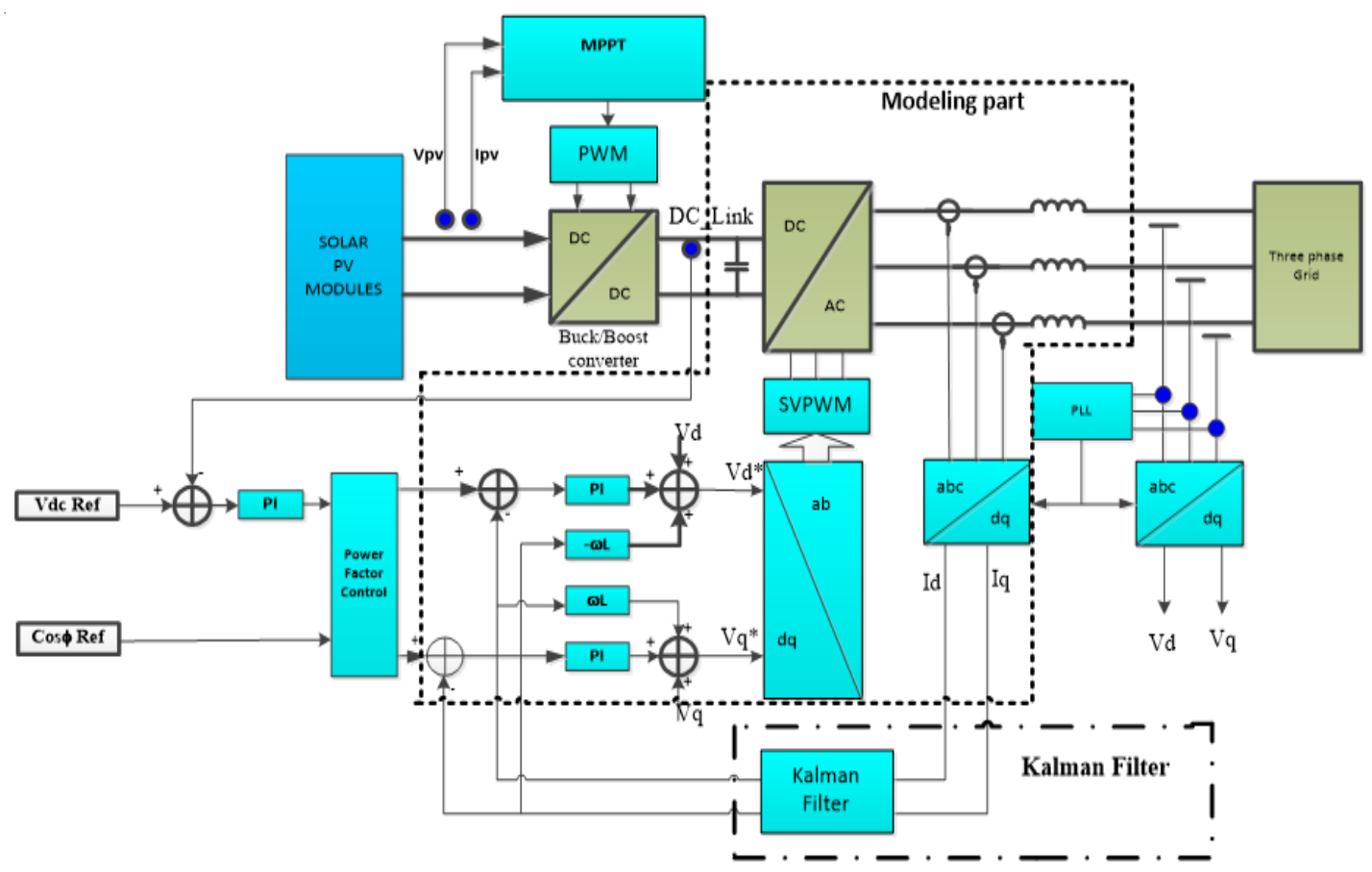

Figure 1: Proposed grid tie inveter model

In this paper, authors focus on two main problems, as designing the PI controller on $\mathrm{dq}$ frame and proposing a Kalman filter based on the inverter model to overcome the output voltage fluctuations caused by harmonics and sensor's noise.

\section{PROPOSED CONTROL STRUCTURE FOR GRID CONNECTED CONVERTER}

Figure 1 shows a typical model of grid connected inverter [9]. The model includes Park transformation, PLL, current and voltage control loop which can see in almost grid tie inverter. The system is built on the dq coordinate with the input conditions such as amplitude and frequency of the grid voltage changes in certain intervals. Typically, the inner loop controller is AC current control while the DC voltage $(\mathrm{Vdc})$ follows the $\mathrm{Vdc}$ reference (Vdc_ref) by using the outer control loop. Called id, iq, ud, uq and vd, vq are the shadows of output current space vector $i$, output voltage space vector $\mathrm{u}$ and grid voltage space vector $\mathrm{v}$ on $\mathrm{dq}$ axis respectively, iq will be set to 0 in case of grid - connected power factor equal to 1 or $\mathrm{id} / \mathrm{iq}$ be constant (iq $\neq 0$ ) incase that the power factor $<1$. Transfer function model is built from the electronic equivalent 3 phase inverter grid:

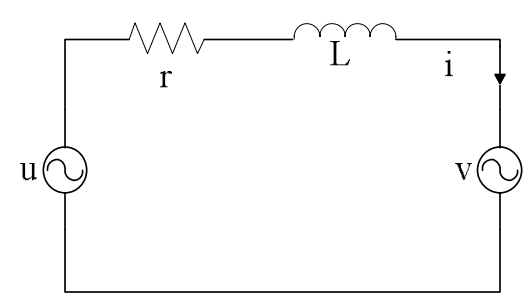

Figure 2: Grid tie currents and voltages

$\mathrm{Dq}$ transformation is performed based on information from the grid voltage. The state space equations were shown below:

$$
\left\{\begin{array}{l}
\dot{x}=A x+B u \\
y=C x
\end{array}\right.
$$

Which: 
$\frac{d}{d t}\left[\begin{array}{l}i_{d} \\ i_{q}\end{array}\right]=\left[\begin{array}{cc}-\frac{r}{L} & \omega \\ -\omega & -\frac{r}{L}\end{array}\right]\left[\begin{array}{l}i_{d} \\ i_{q}\end{array}\right]+\left[\begin{array}{cc}\frac{1}{L} & 0 \\ 0 & \frac{1}{L}\end{array}\right]\left[\begin{array}{l}u_{d}-v_{d} \\ u_{q}-v_{q}\end{array}\right]$

The values of the three-phase current source grid tie inverter model parameters are presented in Table 1.

Table 1: Inverter parameters

\begin{tabular}{|c|c|c|}
\hline Parameter & Value & Explanation \\
\hline $\mathrm{r}$ & $3 \Omega$ & Filter inductance resistor \\
\hline $\mathrm{L}$ & $12 \mathrm{mH}$ & Filter inductance \\
\hline$\omega$ & $100 \pi$ & Grid frequency \\
\hline Fs & $1200 \mathrm{~Hz}$ & Sampling frequency \\
\hline
\end{tabular}

The inverter is control by PWM switching controller with switching frequency approximately $20 \mathrm{kHz}$ and the sampling (parameter update) frequency is $1200 \mathrm{~Hz}$. For simplicity, we can assume that the PWM is a delay block with transfer function:

$$
G_{P W M}(s)=\frac{1}{1+1.5 T_{S} s}
$$

Call wd, wq 2 of the PWM input. We have equations :

$$
\begin{aligned}
& u_{d q}(s)=w_{d q}(s) \frac{1}{1+1.5 T_{s} s} \\
& u_{d q}(t)+1.5 T_{s} \dot{u}_{d q}(t)=w_{d q}(t) \\
& \dot{u}_{d q}(t)=\frac{w_{d q}(t)-u_{d q}(t)}{1.5 T_{s}} \\
& =\frac{w_{d q}(t)-u_{d q}(t)}{1.5} * f_{s} \\
& =800 w_{d q}(t)-800 u_{d q}(t)
\end{aligned}
$$

Put $o_{d q}(t)=u_{d q}(t)$ we have state space equations :

$\left[\begin{array}{l}\dot{o}_{d} \\ \dot{o}_{q}\end{array}\right]=\left[\begin{array}{cc}-800 & 0 \\ 0 & -800\end{array}\right]\left[\begin{array}{l}o_{d} \\ o_{q}\end{array}\right]+\left[\begin{array}{cc}800 & 0 \\ 0 & 800\end{array}\right]\left[\begin{array}{l}w_{d} \\ w_{q}\end{array}\right]$ $\left[\begin{array}{l}u_{d} \\ u_{q}\end{array}\right]=\left[\begin{array}{l}o_{d} \\ o_{q}\end{array}\right]$

Combine (2), (3) and (4)

$$
\begin{aligned}
& \frac{d}{d t}\left[\begin{array}{l}
i_{d} \\
i_{q} \\
o_{d} \\
o_{q}
\end{array}\right]=\left[\begin{array}{cccc}
-250 & 100 \pi & 83.33 & 0 \\
-100 \pi & -250 & 0 & 83.33 \\
0 & 0 & -800 & 0 \\
0 & 0 & 0 & -800
\end{array}\right]\left[\begin{array}{l}
i_{d} \\
i_{q} \\
o_{d} \\
o_{q}
\end{array}\right] \\
&+ {\left[\begin{array}{cccc}
-83.33 & 0 & 0 & 0 \\
0 & -83.33 & 0 & 0 \\
0 & 0 & 800 & 0 \\
0 & 0 & 0 & 800
\end{array}\right]\left[\begin{array}{c}
v_{d} \\
v_{q} \\
w_{d} \\
w_{q}
\end{array}\right] } \\
& {\left[\begin{array}{l}
y_{d} \\
y_{q}
\end{array}\right]=\left[\begin{array}{llll}
1 & 0 & 0 & 0 \\
0 & 1 & 0 & 0
\end{array}\right]\left[\begin{array}{c}
i_{d} \\
i_{q} \\
o_{d} \\
o_{q}
\end{array}\right] }
\end{aligned}
$$

\section{KALMAN FILTER}

To reduced noise from switching process on the sensor, we design the Kalman filter to estimate the output signals of inverter. The Kalman filter estimates a process by using a form of feedback control: the filter estimates the process state at some time and then obtains feedback in the form of (noisy) measurements.

Assume that noise is white noise that includes:

System noise $\mathrm{w}(\mathrm{t})$ : Appearing due to factors of uncertainty in the system and the model's error.

Measurement noise $\mathrm{v}(\mathrm{t})$ : Appearing due to uncertainty from the environment, noise on the grid and having direct affect the measurement of the sensors.

Since the occurrence of noise, system state equation has been changed:

$$
\begin{aligned}
& \left\{\begin{array}{c}
\dot{x}=A x+B u+G w \\
y=C x+v
\end{array}\right. \\
& G=\left[\begin{array}{l}
1 \\
1 \\
1 \\
1
\end{array}\right],
\end{aligned}
$$

Normally, the measurement noise has a great effect on the system's stability. In this paper, authors suppose that there is no system noise then $\mathrm{w}, \mathrm{v}$ is regarded as uncorrelated $\left(\mathrm{E}\left(\mathrm{wv}^{\wedge} \mathrm{T}\right)=0\right)$, with the average value of 0 and variance respectively: 


$$
\begin{aligned}
& \left(w w^{T}\right)=Q=10^{-9} \\
& E\left(v v^{T}\right)=R=\left[\begin{array}{cc}
0.01 & 0 \\
0 & 0.01
\end{array}\right]:
\end{aligned}
$$

Suppose measurement of noise variance with 2 components id, iq are 0.01 .

The Kalman filter "KEST" is calculated based on the model parameters. KEST includes 6 inputs: vdq, udq, ydq, to create value estimated of 6 output values: $\tilde{y}_{d q}, \tilde{\imath}_{d q}, \tilde{o}_{d q}$.

The state space equations of grid tie inverter is shown in equation (5). The PI currents controller was chosen by using loop shaping theory for the singular values plot of shaped loop have to have high gain at low frequency $(5 \mathrm{~Hz})$ and low gain at high frequency $(500 \mathrm{~Hz})$, the singular plot of target system are shown in figure 4 and 5 .

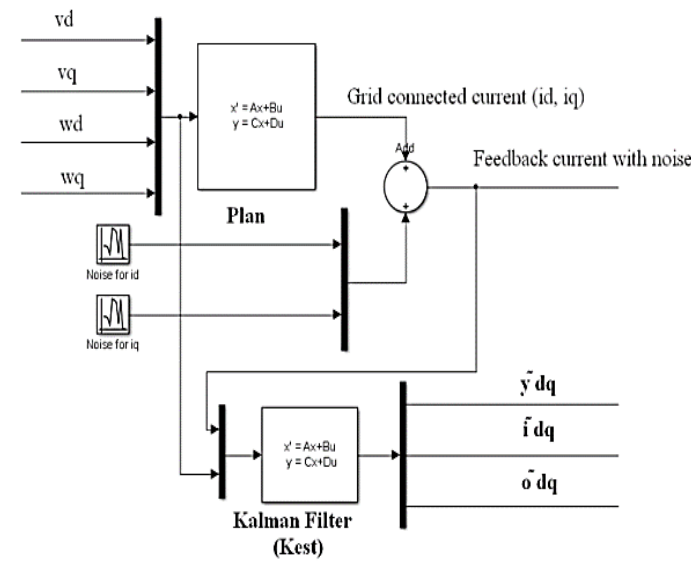

Figure 3: Kalman filter

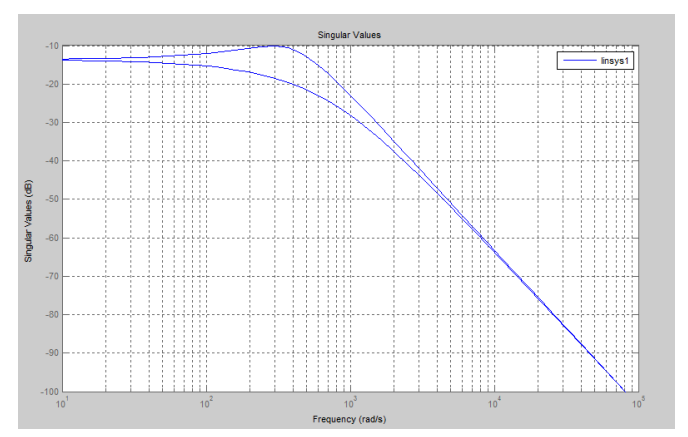

Figure 4: Singular value plots of system before adjusting

\section{SIMULATION RESULT}

The simulation parameters including $250 \mathrm{Wp}$ solar panels, DC voltage will be fixed at 100VDC, grid voltage $\mathrm{vd}=90 \mathrm{~V}, \mathrm{vq}=0 \mathrm{~V}$, the grid tie current is controlled with constant ratio: $\mathrm{Id} / \mathrm{Iq}=$ 2.

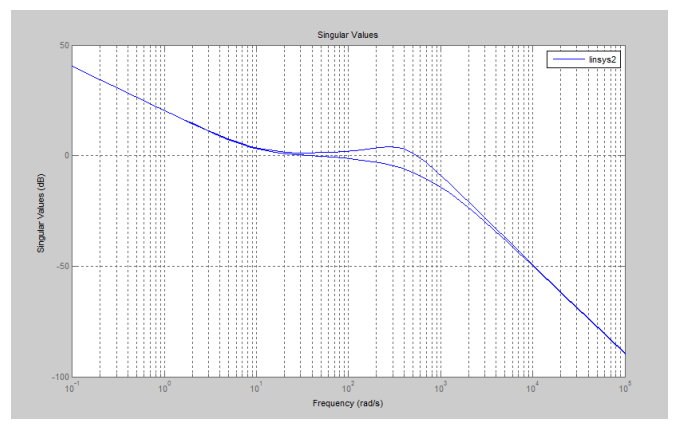

Figure 5: Singular value plots of system after adjusting

Simulation 1: Simulation in case without sensors noise and Kalman filter.

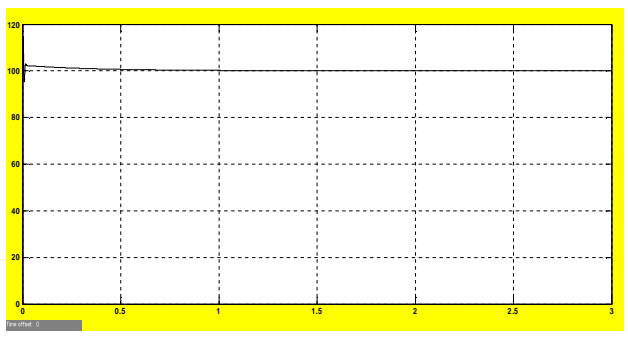

(a)

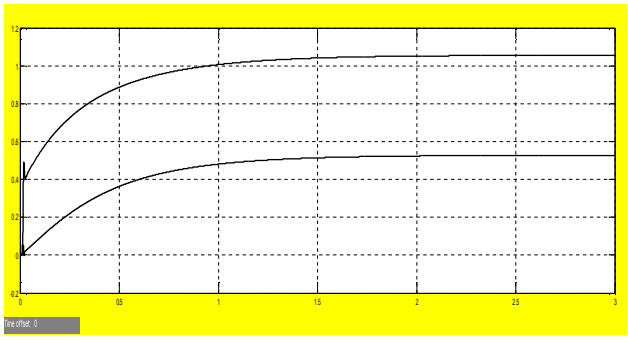

b)

Figure 6: System DC voltage (a) and feedback currents(b) in ideal condition.

Simulation 2: Simulation in case the output noise with variance 0.01 without Kalman filter. 


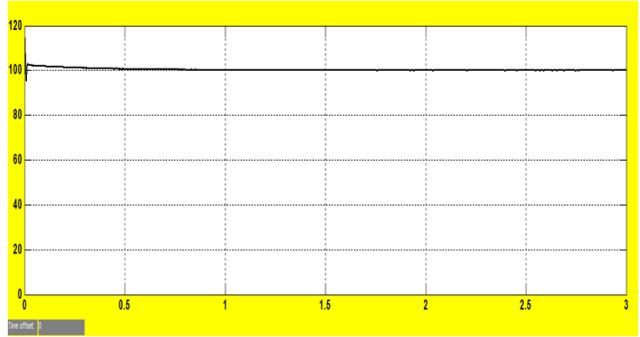

a)

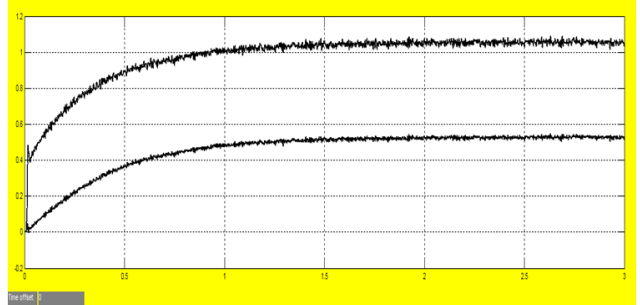

b)

Figure 7: DC voltage (a) and feedback current (b) in case having sensor noise without filtering

Simulation 3: Simulation in case the output noise with variance 0.01 , with Kalman filter

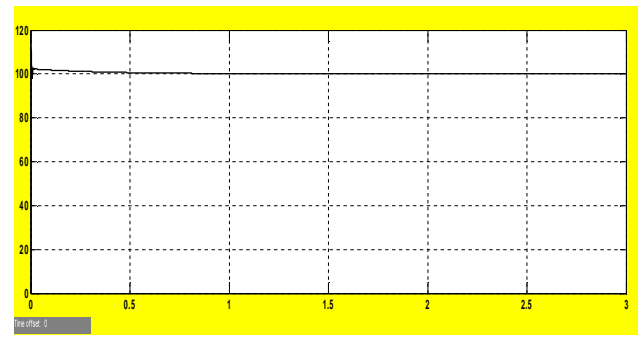

a)

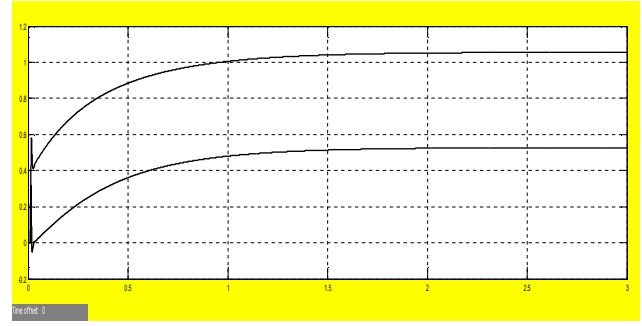

b)

Figure 8: DC voltage (a) and feedback current (b) in case having sensor noise with Kalman filtering

Simulation 1, 2 and 3 show the importance of Kalman filter. The sensor noise which will always appear in power system can be canceled by using a soft filter.

\section{CONCLUSION}

This paper proposes the Kalman filter for sensor noise cancelation. With the Kalman, the disturbance appear during measurement can be eliminated, thus better system response. By using software filters, we can reduce hardware noise filter which usually cause phase delay and expensive. Moreover, we can use cheaper sensors but system still achieves quality and stability.

\section{ACKNOWLEDGEMENT}

We would like to express our sincere thanks and appreciation both to Power Electronics Lab (PERL) and Vietnam National University Ho Chi Minh City (VNU - HCM) for their helps. This research is funded by VNU-HCM under grant number B2014-20-06.

\section{Trang 196}




\section{Ứng dụng bộ lọc Kalman lọc nhiễu của cảm biến trong bộ nghịch lưu kểt nối lưới}

- Nguyễn Minh Huy

- Lê Minh Phương

- Hồ Thanh Phương

Trường Đại học Bách Khoa, ĐHQG-HCM, Việt Nam

\section{TÓM TÁT}

Bài báo đưa ra mô hình bộ nghịch lưu kết nối lưới dựa trên việc phân tích bộ nghịch lưu hòa lưới dạng biến tần 3 pha, 2 bậc. Mô hình toán và mô hình điều khiển tổng quát của hệ thống được xây dựng trên hệ trục tọa độ $d q$. Bài báo đề xuất bộ lọc Kalman ứng dụng

Từ khóa: Bộ lọc Kalman, nghịch lưu hòa lưới, nhiễu cảm biến.

\section{REFERENCES}

[1]. J. C. Schaefer, "Review of photovoltaic power plant performance and economics," IEEE Trans. Energy Convers., vol. 5, no. 2, pp. 232238, Jun. 1990.

[2]. E. V. Solodovnik, S. Liu, and R. A. Dougal, "Power controller design for maximum power tracking in solar installations," IEEE Trans. Power Electron., vol. 19, no. 5, pp. 1295-1304, Sep. 2004.

[3]. Weimin Wu; Min Huang; Yunjie Sun; Xiongfei Wang; Blaabjerg, F., "A composite passive damping method of the LLCL-filter based grid-tied inverter," Power Electronics for Distributed Generation Systems (PEDG), 2012 3rd IEEE International Symposium on , vol., no., pp.759,766, 25-28 June 2012

[4]. H. Akagi, Y. Kanazawa, A. Nabae, "Instantaneous reactive compensators comprising switching devices without Energy Storage components", IEEE Trans. On trong việc loại bỏ nhiễu xuất hiện trên cảm biến do việc đóng cắt ở tần số cao gây ra. Mô hình hệ thống được kiểm chứng trên Matlab - Simulink với kết quả tốt, nâng cao chất lượng điện áp hòa lưới.
Industry Applications.vol. IA-20, No.3, pp.625-630, May / June, 1984

[5]. arthinus G. F. Gous, Hendrik J. Beukes, "Sliding mode control for a three phase shunt active power filter utilizing a four leg voltage source inverter", 35th Annual IEEE power elect. Sp. Conf., Aachen, Germany, 2004

[6]. Elangovan, S., "Active Power Filter Solution without PLL for Fluctuating Industrial Load," Power Electronics, Drives and Energy Systems, 2006. PEDES '06. International Conference on , vol., no., pp.1,6, 12-15 Dec. 2006

[7]. C. Busada and S. Jorge, "Current controller based on reduced order generalized integrators for distributed generation systems, "IEEE Transactions on Industrial Electronics, vol. 59, no. 7, pp. 2898-2909, 2012

[8]. P. Rodriguez, A. Luna, I. Candela, R. Teodorescu, and F. Blaabjerg, "Grid 
synchronization of power converters using multiple second order generalized integrators,"Industrial Electronics, 2008. IECON 2008. 34 $4^{\text {th }}$ Annual Conference of IEEE, pp. 755-760, 2008
[9]. Liang Ma; Wang Ran; Zheng, T.Q., "Modeling and control of $100 \mathrm{~kW}$ three-phase gridconnected photovoltaic inverter," Industrial Electronics and Applications (ICIEA), 2010 the 5th IEEE Conference on, vol., no., pp.825,8 30, 15-17 June 2010. 